\title{
Rho inhibition by lovastatin affects apoptosis and DSB repair of primary human lung cells in vitro and lung tissue in vivo following fractionated irradiation
}

\author{
Verena Ziegler ${ }^{1}$, Christian Henninger ${ }^{1}$, loannis Simiantonakis ${ }^{2}$, Marcel Buchholzer ${ }^{3}$, Mohammad Reza Ahmadian ${ }^{3}$, Wilfried Budach ${ }^{2}$
} and Gerhard Fritz ${ }^{* 1}$

Thoracic radiotherapy causes damage of normal lung tissue, which limits the cumulative radiation dose and, hence, confines the anticancer efficacy of radiotherapy and impacts the quality of life of tumor patients. Ras-homologous (Rho) small GTPases regulate multiple stress responses and cell death. Therefore, we investigated whether pharmacological targeting of Rho signaling by the HMG-CoA-reductase inhibitor lovastatin influences ionizing radiation (IR)-induced toxicity in primary human lung fibroblasts, lung epithelial and lung microvascular endothelial cells in vitro and subchronic mouse lung tissue damage following hypo-fractionated irradiation (4x4 Gy). The statin improved the repair of radiation-induced DNA double-strand breaks (DSBs) in all cell types and, moreover, protected lung endothelial cells from IR-induced caspase-dependent apoptosis, likely involving p53-regulated mechanisms. Under the in vivo situation, treatment with lovastatin or the Rac1-specific small molecule inhibitor EHT1864 attenuated the IR-induced increase in breathing frequency and reduced the percentage of $\gamma \mathrm{H} 2 \mathrm{AX}$ and 53BP1-positive cells. This indicates that inhibition of Rac1 signaling lowers IR-induced residual DNA damage by promoting DNA repair. Moreover, lovastatin and EHT1864 protected lung tissue from IR-triggered apoptosis and mitigated the IR-stimulated increase in regenerative proliferation. Our data document beneficial anti-apoptotic and genoprotective effects of pharmacological targeting of Rho signaling following hypo-fractionated irradiation of lung cells in vitro and in vivo. Rac1-targeting drugs might be particular useful for supportive care in radiation oncology and, moreover, applicable to improve the anticancer efficacy of radiotherapy by widening the therapeutic window of thoracic radiation exposure.

Cell Death and Disease (2017) 8, e2978; doi:10.1038/cddis.2017.372; published online 10 August 2017

Radiation therapy (RT) is a frequently used treatment modality for thoracic malignancies. However, its therapeutic efficacy is limited because of adverse effects on normal lung tissue, resulting in radiation-induced lung injury (RILI). RILI manifests as lung inflammation or fibrosis weeks to years after RT. More sophisticated RT techniques (e.g., conformal RT or intensitymodulated RT) allow better tumor control whilst sparing normal tissue. ${ }^{1}$ In addition, pharmacological strategies to prevent RILI are preferential because they would allow the application of higher cumulative radiation doses, thereby further improving local tumor control and, moreover, improving the quality of life of cancer patients. In view of clinical translation of preclinical data in a timely manner, off-label use of already approved drugs appears desirable.

Statins are such promising class of drugs because they are frequently used for lipid-lowering purpose and are well tolerated. All statins have in common that they interfere with the rate-limiting step in the synthesis of cholesterol by inhibiting the conversion of 3-hydroxy-3-methylglutaryl coenzyme A (HMG-CoA) by the HMG-CoA reductase. In consequence, the cellular pool of isoprene moieties (i.e., geranyl- and farnesylpyrophosphate) is depleted. In addition to cholesterol biosynthesis, isoprene residues are also required for C-terminal prenylation and membrane localization of regulatory proteins, notably Ras-homologous small GTPases (Rho-GTPases). Therefore, the pleiotropic effects of statins are believed to mainly result from the inhibition of Rho-GTPases, ${ }^{2,3}$ in particular $\mathrm{RhoA}^{4}$ and Rac1. ${ }^{5,6}$ Apart from exhibiting anticancer effects in vitro and in vivo $^{7-9}$ statins also mitigate normal tissue damage evoked by anticancer therapeutics and irradiation. For instance, lovastatin protects cardiomyocytes from the anthracycline derivative doxorubicin., ${ }^{6-12}$ Moreover, statins are radioprotective in vitro ${ }^{13}$ and in vivo. ${ }^{14-16}$ However, in most of these studies, the impact of statins on anticancer therapyinduced normal tissue damage was investigated in acute models, that is, after single treatment with high doses and analysis at early time points after exposure. The influence of statins on adverse late responses resulting from fractionated irradiation of the lung is unknown. Moreover, it is unclear which cell type of the lung is particularly sensitive to fractionated irradiation and, hence, might be of major relevance for the pathophysiology of RILI and, correspondingly, could be targeted for radioprotection.

In the present study we investigated (i) the effects of lovastatin on different types of confluent (non-growing)

\footnotetext{
${ }^{1}$ Institute of Toxicology, Medical Faculty, Heinrich Heine University Duesseldorf, Moorenstrasse 5, Duesseldorf, Germany; ${ }^{2}$ Department of Radiotherapy and Radiation Oncology, University Hospital Duesseldorf, Moorenstraße 5, Duesseldorf, Germany and ${ }^{3}$ Institute of Biochemistry and Molecular Biology II, Medical Faculty, Heinrich Heine University, Duesseldorf, Germany

${ }^{*}$ Corresponding author: G Fritz, Institute of Toxicology, Heinrich Heine University Duesseldorf, Moorenstrasse 5, 40225 Düsseldorf, Germany. Tel: +49 2218113022 ; Fax: +49 22181 13013; E-mail: fritz@uni-duesseldorf.de

Received 16.3.17; revised 22.6.17; accepted 02.7.17; Edited by A Stephanou
} 
primary human lung cells following fractionated irradiation in vitro and (ii) the impact of lovastatin and the Rac1-specific small molecule inhibitor EHT1864 on RILI analyzed four weeks after fractionated lung irradiation in vivo. EHT1864 was included to figure out the specific relevance of Rac1-regulated signaling mechanisms for statin-mediated effects.

\section{Results}

Analysis of radioprotective effects of lovastatin in primary human lung cells. So far radioprotective effects of statins were mostly investigated under acute settings, applying single and high radiation doses. This poorly mimics the clinical relevant situation of radiotherapy. Here, we applied a hypo-fractionated irradiation protocol and analyzed delayed lung toxicity in vitro (Figure 1a) and in vivo (Figure 4b). Regarding the in vitro analyses, we used different types of primary human lung cells and performed the experiments at cell confluency as confirmed by microscopy (Figure 1d) and measurement of mitotic index (Figures $1 \mathrm{~b}$ and $\mathrm{c}$ ). Upon fractionated irradiation ( $4 \times 4$ Gy, every $24 \mathrm{~h}$ ) of microvascular endothelial cells of the lung (HMVEC-L), pulmonary fibroblasts (HPF) or small airway epithelial cells (HSAEpC) we observed significant cytotoxicity only in HMVEC-L as shown by microscopical analysis (Figure 1d) and analysis of apoptosis by Annexin V-based method (Figures 1e-g). We assume that pulmonary fibroblasts and epithelial cells preferentially activate mechanisms of senescence following radiation. ${ }^{17,18}$ Co-treatment with low doses of lovastatin completely prevented apoptosis induction in HMVEC-L (Figure 1e). Fractionated irradiation decreased the protein level of pro-caspase 3, increased the levels of cleaved caspases 3 and 7 and promoted PARP-1 cleavage (Figure 2a). Lovastatin mitigated activation of caspases and PARP cleavage (Figure 2a). Protein expression of Bax, $\mathrm{Bcl}-2$ and XIAP remained unchanged in all experimental groups (Figure 2a). Fractionated irradiation-induced apoptosis of HMVEC-L was accompanied by slightly increased mRNA expression of Bax and substantial increase in Fas receptor

a

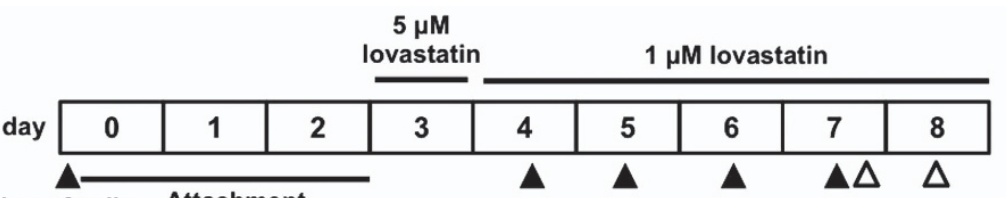

Seeding of cells Attachment

Irradiation (4 x 4 Gy) YH2AX foci, Annexin V/PI staining, Western blotting, mRNA analysis

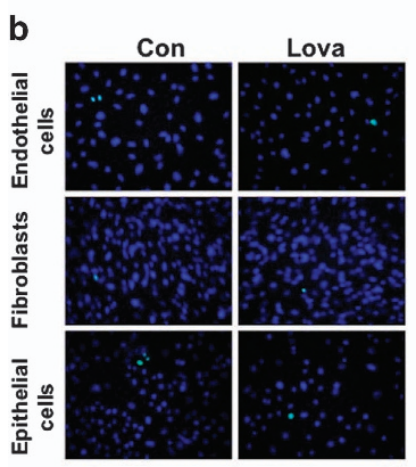

c
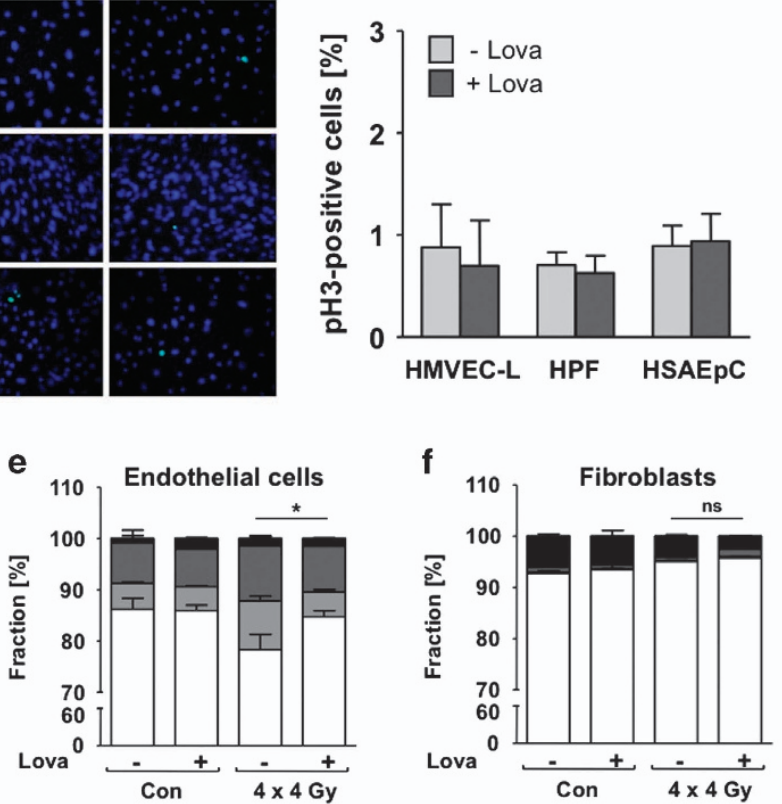
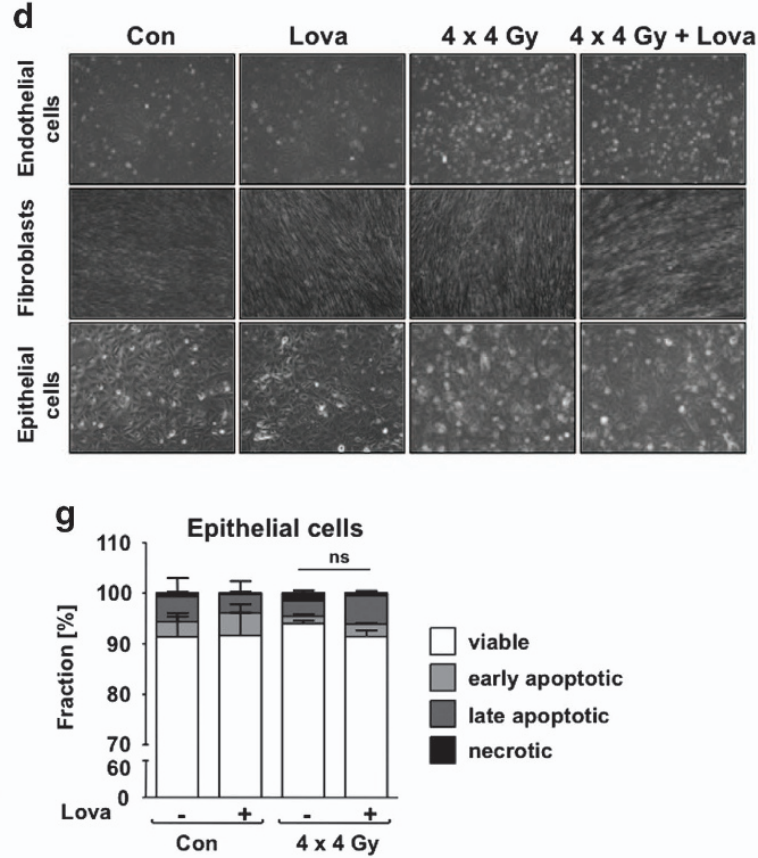

Figure 1 Fractionated irradiation does not induce apoptosis in confluent primary human lung epithelial cells or lung fibroblasts, but leads to apoptotic cell death in lung endothelial cells, which is prevented by lovastatin. Human microvascular endothelial cells of the lung (HMVEC-L), human pulmonary fibroblasts (HPF) and human small airway epithelial cells (HSAEpC) were seeded in high density and grown to confluency before lovastatin (Lova) $(5 \mu \mathrm{M})$ pretreatment. After incubation period of $24 \mathrm{~h}$, lovastatin concentration was reduced $(1 \mu \mathrm{M})$ and irradiation was performed $(4 \times 4 \mathrm{~Gy})$ as described in methods. Control cells were vehicle-treated and subjected to sham irradiation. (a) Treatment scheme. (b,c) pH3 staining (= mitotic index) after $24 \mathrm{~h}$ pre-incubation with lovastatin $(5 \mu \mathrm{M})$ to verify cell confluency. Shown are representative images $(\mathbf{b})$ and quantitative data (c). (d) Analysis of cell morphology $24 \mathrm{~h}$ after the last irradiation. (e-g) Apoptosis was measured by Annexin V/PI staining $24 \mathrm{~h}$ after the last irradiation. Data show the mean \pm S.D. from $n=2-3$ independent experiments. Annexin $\mathrm{V}$ positive/PI-negative cells are considered as early apoptotic, Annexin $\mathrm{V}$ negative/PI-positive cells as necrotic. Two-way ANOVA with Bonferroni post hoc test. ${ }^{*} P \leq 0.05$ IR versus IR+Lova 

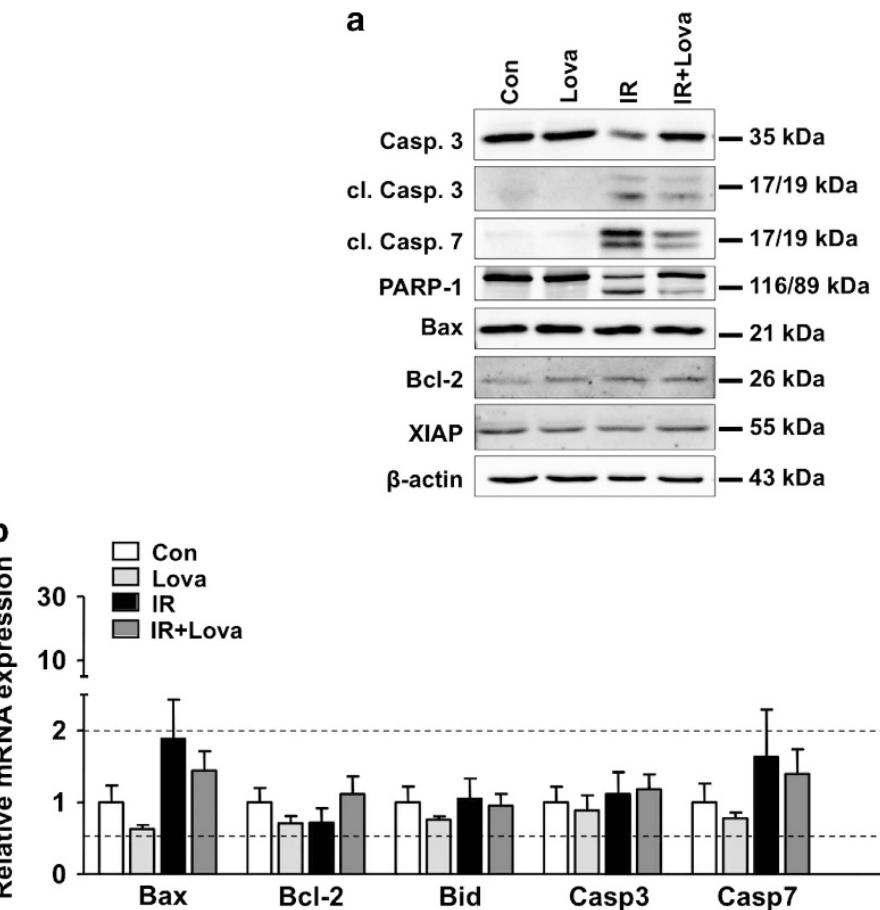

Figure 2 Fractionated irradiation causes activation of caspases in human lung endothelial cells, which is attenuated by lovastatin. Human microvascular endothelial cells of the lung (HMVEC-L) were seeded in high density and grown to confluency before lovastatin (Lova) $(5 \mu \mathrm{M})$ pretreatment. After incubation period of $24 \mathrm{~h}$, lovastatin concentration was reduced $(1 \mu \mathrm{M})$ and irradiation was performed (4x4 Gy) as described in methods. Control cells were vehicle-treated and subjected to sham irradiation. (a) Protein extracts were harvested $24 \mathrm{~h}$ after the last irradiation and analyzed for the expression of pro-caspase 3 (Casp. 3), cleaved caspase 3 (cl. Casp. 3), cleaved caspase 7 (cl. Casp. 7 ), Poly (ADP-ribose)-polymerase 1 (PARP-1) as well as of Bax, Bcl-2 and XIAP. Expression of $\beta$-actin was used as loading control. (b) mRNA levels of Bax, Bcl-2, Bid, caspases 3 (Casp3) and 7 (Casp7) as well as of Fas ligand (FasL) and Fas receptor (FasR) were analyzed six hours after the last irradiation using quantitative real-time PCR. Results are shown as mean \pm S.D. of a representative experiment performed in triplicates. mRNA expression of $\geq 2$ and $\leq 0.5$ as compared with control (set to 1.0$)$ are marked with dashed lines. n.d., not detectable

(FasR) expression (Figure 2b), which again was partially reduced by lovastatin (Figure $2 \mathrm{~b}$ ). Overall, the data indicate that fractionated irradiation triggers caspase-dependent and lovastatin-sensitive death pathways preferentially in lung endothelial cells.

\section{Lovastatin protects lung cells from DNA damage induced} by fractionated irradiation. DNA double-strand breaks (DSBs) are major cytotoxic lesions induced by IR and effectively trigger apoptosis or senescence. ${ }^{19,20}$ Nuclear $y \mathrm{H} 2 \mathrm{AX}$ (Ser139 phosphorylated histone H2AX) foci are commonly used surrogate markers of DSBs. ${ }^{21}$ All lung cell types revealed a similar initial number of $\mathrm{\gamma H} 2 \mathrm{AX}$ foci (Figures $3 \mathrm{a}$, $b, d$ and f), which was unaffected by the statin. Hence, we hypothesize that lung cells form identical levels of initial DSBs but differ from each other regarding complex DNA damagetriggered pro-apoptotic signaling mechanisms. ${ }^{22}$ After postincubation period of $24 \mathrm{~h}$, significantly lower DSB levels were found in the lovastatin co-treated groups (Figures 3c, e and g), showing that the statin accelerates the repair of DSBs. The number of residual $\mathrm{YH} 2 \mathrm{AX}$ foci in the absence of lovastatin was 2-3-fold higher in epithelial cells as compared with endothelial cells and fibroblasts (Figures 3c, e and g), indicating that epithelial cells have the lowest DSBs repair capacity. Apparently, lovastatin favors the repair of IR-induced potentially lethal damage especially in lung endothelial cells.
Lovastatin did not reduce the radiation-stimulated increase in pATM protein, a key regulator of the DNA damage response (DDR), and its substrate pKap1 (Figure 3h). Protein levels of pp53, which were also increased following IR treatment, were lower in statin-treated lung fibroblasts and epithelial cells, but were largely unaffected in endothelial cells (Figure 3h), supporting the view of cell type-specific effects of fractionated irradiation and statins on lung cells.

Response of HUVEC and MRC-5 cells to fractionated irradiation. Including primary human umbilical vein endothelial cells (HUVEC) and human fetal lung fibroblasts (MRC-5 cells) in our study, similar results were obtained as with primary lung cells. Whereas HUVEC revealed a substantially elevated frequency of apoptotic cells following fractionated irradiation, which was reduced by lovastatin (Supplementary Figure 1A), apoptosis was not triggered in MRC-5 cells (Supplementary Figure 2A). However, both cell types showed accelerated repair of DSBs if lovastatin was present (Supplementary Figures $1 \mathrm{~B}$ and 2B). Moreover, IRstimulated DDR was affected by lovastatin in both cell types, as detectable on the levels of pKap1 and pp53 (Supplementary Figures $1 \mathrm{C}$ and $2 \mathrm{C}$ ). The data demonstrate that the response of confluent primary human cells to hypofractionated irradiation is cell type-specific: a substantial apoptotic response occurs in lung microvascular endothelial 

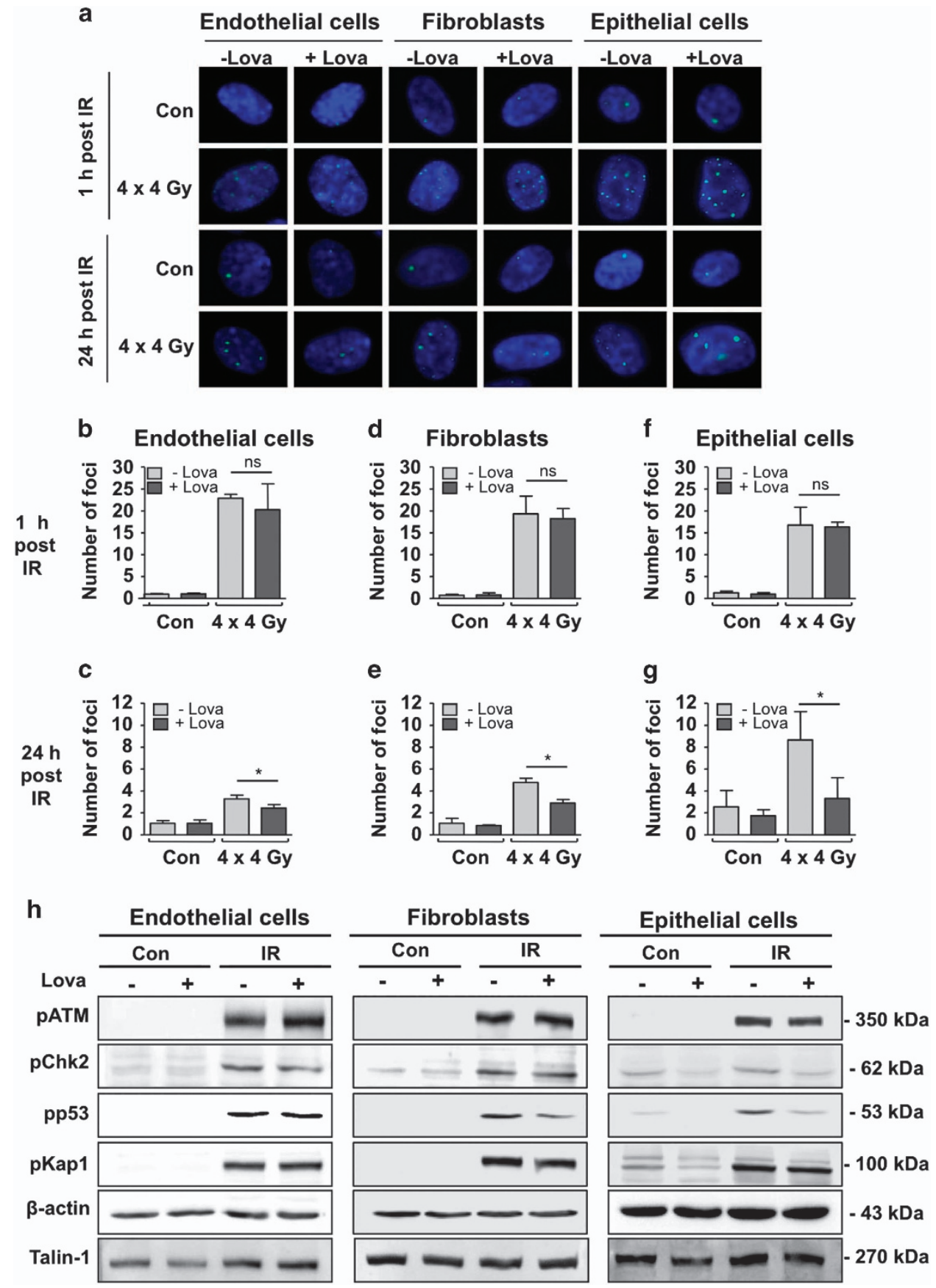

Figure 3 Lovastatin has no influence on initial DNA double-strand break (DSB) formation following fractionated irradiation. However, it lowers the amount of residual DNA DSBs and impacts mechanisms of the DDR in primary human lung cells. Non-growing HMVEC-L, HPF and HSAEpC were treated as described before (Figure 1a). The number of nuclear $\gamma \mathrm{H} 2 \mathrm{AX}$ foci was analyzed by immunocytochemical staining. (a) Representative images. green, $\gamma \mathrm{H} 2 \mathrm{AX}$ foci; blue, DAPI. (b-g) Number of $\gamma \mathrm{H} 2 \mathrm{AX}$ foci detectable $1 \mathrm{~h}$ $(\mathbf{b}, \mathbf{d}, \mathbf{f})$ and $24 \mathrm{~h}(\mathbf{c}, \mathbf{e}, \mathbf{g})$ after the last irradiation. Shown are the mean \pm S.D. from $n=2-3$ independent experiments. Two-way ANOVA with Bonferroni post hoc test. ${ }^{*} P \leq 0.05 \mathrm{IR}$ versus IR+Lova. (h) One hour after the last irradiation the activation status of a subset of key proteins of the DNA damage response was investigated by Western blot analysis. Shown are the protein levels of Ser1981 phosphorylated ATM (pATM), Thr68 phosphorylated checkpoint kinase-2 (pChk2), Ser15 phosphorylated protein 53 (pp53), Ser824 phosphorylated KRAB-associated protein-1 (pKap1). Expression of $\beta$-actin and Talin-1 were used as loading controls

and umbilical vein endothelial cells but not in lung fibroblasts or lung epithelial cells. However, independent of the cell type, lovastatin accelerates the repair of radiation-induced DSBs.

Fractionated lung irradiation in vivo: effects on body weight and breathing frequency. To address the question whether lovastatin is radioprotective in vivo, we aimed to selectively irradiate the right lung of mice without profuse concomitant irradiation of the left lung or other non-target organs. We established an irradiation device (Figure 4a) that is shielding other tissues (i.e., left lung, heart, liver) using CT-based 3D modeling. One hour after single irradiation 

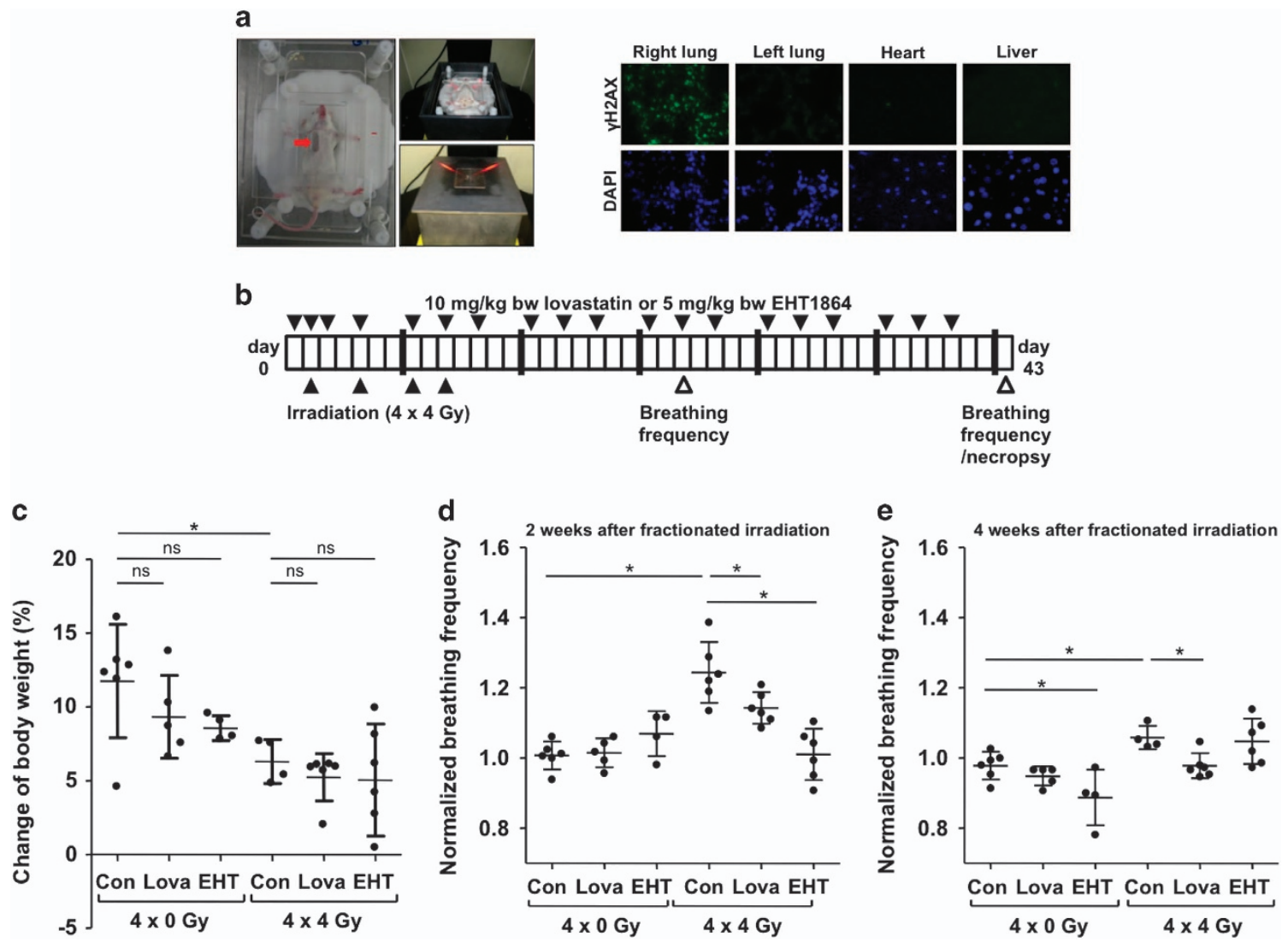

Figure 4 Fractionated irradiation of the lung leads to a reduced gain of body weight and an increased breathing frequency two weeks after irradiation. Lovastatin and EHT1864 treatment have no effect on body weight, but decrease IR-mediated increase in breathing frequency. (a) Selective irradiation of the right mouse lung was achieved using a metal-free device, which is adjustable in $x-, y$ - and $z$-direction. $6 \mathrm{~mm}$ lead shielding prevents irradiation of other tissue. The red arrow marks the radiation field. One hour after single irradiation (4 Gy) of the right lung of anesthesized BALB/c mice, different tissues (lung, heart, liver) were analyzed for the presence of $\gamma \mathrm{H} 2 \mathrm{AX}$ foci, which are indicative of DSBs. Nuclei were counterstained with DAPI. Shown are representative photographs. (b) Treatment scheme. As based on previous in vivo studies ${ }^{6,14,66,67}$ male BALB/c mice were treated three times per week with lovastatin (10 mg/kg BW) or the Rac1-specific small molecule inhibitor EHT18641 (5 mg/kg BW) during a total period of six weeks. In the course of the first two weeks the right lung of the animals was irradiated four times with each $4 \mathrm{~Gy}(4 \times 4 \mathrm{~Gy})$, resulting in a cumulative dose of 16 Gy. Control animals were not irradiated ( $4 \times 0$ Gy). (c) Body weight was recorded three times per week. Data shown are changes in percent of body weight between the start and end of the experiment. Shown are the mean \pm S.D. of $n=4-6$ animals per experimental group. Two-way ANOVA with Bonferroni post hoc test, ${ }^{*} P \leq 0.05$. ns, not significant. (d,e) Breathing frequency, which is indicative of radiation pneumonitis, ${ }^{24,25,68}$ was determined two weeks (d) and four weeks (e) after the end of the fractionated irradiation. Breathing frequency of control animals was set to 1. Mean \pm S.D. of $n=4-6$ animals per experimental group. Two-way ANOVA with Bonferroni post hoc test, ${ }^{*} P \leq 0.05$

(4 Gy) the frequency of $\gamma \mathrm{H} 2 \mathrm{AX}$-positive cells was specifically increased in the right lung but not in other adjacent tissues (Figure 4a), demonstrating the accuracy of our radiation device.

To investigate delayed radiation-induced lung injury, the right lung of male BALB/c mice was subjected to hypo-fractionated irradiation in the presence or absence of lovastatin or the Rac-specific inhibitor EHT1864 $4^{23}$ (Figure 4b). Irradiation slightly slowed down the gain of body weight during the evaluation period (Figure 4c), which was not affected by lovastatin and EHT1864. The moderate radiation effect on body weight is indicative of a low general radiotoxicity. Breathing frequency, which is widely used as indication of lung function (e.g., radiation-induced pneumonitis), ${ }^{24-26}$ was elevated by $\sim 20 \%$ in the irradiated group two weeks after the last irradiation (Figure 4d). While lovastatin reduced the breathing frequency only slightly, inhibition of Rac1 by EHT1864 caused a more pronounced normalization of breathing frequency (Figure 4d). Four weeks after the last irradiation, breathing frequency was only marginally elevated in the irradiated group (Figure 4e).

Fractionated lung irradiation ( $4 x 4$ Gy) does not cause sustained inflammation or oxidative stress. Lung sections stained with hematoxylin/eosin or Sirius Red showed no obvious inflammatory cell infiltrates or fibrotic lesions, respectively (Supplementary Figures $3 \mathrm{~A}$ and $\mathrm{B}$ ), indicating that fractionated irradiation does not cause sustained inflammatory or fibrotic processes. qRT-PCR-based mRNA expression analyses showed similar results (Supplementary Figure 4). Only IL-1a, MMP2 and MPO exhibited a slight mRNA upregulation in the irradiated group as compared with sham-treated controls (Supplementary Figure 4). Lovastatin and EHT1864 had no effect. A 2-3-fold increase in the number of CD68-positive cells (i.e., alveolar macrophages ${ }^{27}$ ) was observed in the irradiated group (Supplementary Figures 
$3 C$ and D), which was neither influenced by lovastatin nor EHT1864 (Supplementary Figure 3D). As irradiation also triggers the generation of reactive oxygen species (ROS), we investigated oxidative stress by measuring the expression of major factors of the antioxidative defense system, which is majorly regulated by the transcription factor Nuclear Factor (erythroid-derived 2)-like 2 (Nrf2). ${ }^{28}$ Immunohistological staining of Nrf2 in irradiated animals did not reveal any increase in protein level (Supplementary Figure 5A). Likewise, the mRNA expression of prototypical Nrf2 target genes such as glutathione peroxidase-1 (GPX1), heme oxygenase1 (HO-1) and glutathion-S transferase (GSTM1) remained unchanged in irradiated lung tissue (Supplementary Figure 5B). Protein and mRNA expression of manganese superoxide dismutase (MnSOD), which is radioprotective in lung, ${ }^{29-31}$ was also not influenced by our irradiation protocol (Supplementary Figures 5B and C). Noteworthy yet, GPX1 and $\mathrm{HO}-1$ mRNA expression were upregulated in human lung endothelial cells (HMVEC-L) following fractionated irradiation in vitro (Supplementary Figure 5D). Lovastatin reduced the irradiation-induced upregulation of both genes in HMVEC-L. Thus, although it appears questionable that ROS is a major trigger of chronic lung toxicity following fractionated irradiation, its contribution to lung damage cannot be ruled out.

Lovastatin and EHT1864 reduce IR-induced cell death of lung cells in vivo. Apoptosis of lung cells is a hallmark of RILI. ${ }^{27}$ Fractionated irradiation caused a 6-fold increase in the number of apoptotic (i.e., TUNEL positive) cells in the irradiated group (Figures $5 \mathrm{a}$ and b), which was mitigated by lovastatin and EHT1864 (Figure 5b). On protein level, no radiationinduced increase in the cleavage of caspases or PARP-1 was observed (Supplementary Figure 6B). Only the mRNA expression of Bax and caspase 7 was slightly increased in irradiated animals, which was attenuated by lovastatin and EHT1864 cotreatment (Figure 5g). Fractionated lung irradiation raised the mitotic index (=frequency of phospho-histone H3 (Ser10) positive cells), which is indicative of regenerative proliferation, in the lung (Figures $5 \mathrm{c}$ and d). Again, both lovastatin and EHT1864 largely prevented this radiation effect. Analyzing the expression of proliferating cell nuclear antigen (PCNA), another surrogate marker of proliferation, identical results were obtained (Figures $5 e$ and f).

Lovastatin and EHT1864 lower IR-induced residual DNA damage in lung tissue. IR-induced DNA double-strand breaks (DSBs) are vastly detrimental DNA lesions and effectively trigger cell death. ${ }^{32}$ Following fractionated lung irradiation an about 8-fold increased frequency of $\gamma \mathrm{H} 2 \mathrm{AX}$ focipositive cells was found (Figures $6 a$ and b). Lovastatin reduced the IR-induced DNA damage by about $30 \%$. This radioprotective effect was even more pronounced $(\sim 50 \%)$ by EHT1864. Identical results were obtained upon analysis of nuclear 53BP1 foci (Figures $6 \mathrm{c}$ and $\mathrm{d}$ ), another surrogate marker of DSBs. The non-irradiated left lung showed no elevated number of $\gamma \mathrm{H} 2 \mathrm{AX}$ foci expressing cells (Supplementary Figure 7), ruling out the possibility of delayed DNA damaging effects in non-irradiated adjacent tissue. In conclusion, lovastatin and EHT1864 lower the number of lung cells with residual DSBs resulting from fractionated irradiation.
Influence of lovastatin and EHT1864 on IR-activated DDR in vivo. Cells respond to the induction of DSBs with the activation of the ATM (Ataxia telangiectasia mutated) protein kinase, a key regulator of the DDR that coordinates DNA repair and apoptosis. ${ }^{33-35}$ The protein levels of phosphorylated ATM and its prototypical substrates p53 and the heterochromatin protein Kap-1 were elevated in total lung tissue extracts of irradiated animals as compared with nonirradiated controls (Figure 7). Protein expression of activated ATR (pATR) and checkpoint kinase 1 (pChk1), which are key players in the regulation of replicative stress responses, was not detectable under our experimental conditions (data not shown). Phosphorylation of DDR factors in the irradiated mice remained largely unaffected by lovastatin and EHT1864 (Figures 7a and b). Only the IR-induced increase in pATM was significantly reduced by EHT1864 (Figure 7b). Regarding pp53 levels, the statin and EHT caused a slight reduction (Figure 7b). Summarizing, fractionated irradiation results in a sustained activation of DDR factors in lung tissue, which is partially affected by lovastatin or EHT1864.

\section{Discussion}

HMG-CoA reductase inhibitors (statins) have multiple cholesterol-independent effects by interfering with RhoGTPases. ${ }^{2}$ Inhibition of Rho signaling by statins is radioprotective in umbilical vein endothelial cells in vitro ${ }^{13}$ and in an acute rat model of radiation enteritis, ${ }^{15,16}$ with Rho-associated kinase (ROCK) being involved. Cytoprotective properties of statins on acute lung injury have been demonstrated using intratracheal instillation of the radiomimetic bleomycin, ${ }^{36,37}$ single high-dose thorax irradiation ${ }^{14,38}$ or total body irradiation. ${ }^{39}$ Here, we investigated delayed radiotoxicity resulting from fractionated irradiation employing both in vitro and in vivo model systems. We found that human lung microvascular endothelial cells are characterized by a higher frequency of radiation-induced caspase-mediated apoptosis as compared with lung fibroblasts or lung epithelial cells, indicating that especially injury of endothelial cell-related functions contributes to RILI. Since radiation-induced damage to endothelial cells is also mitigated by atorvastati ${ }^{40}$ and pravastatin, ${ }^{41}$ we hypothesize that radiation triggered caspase-mediated death and its prevention by statins is particularly relevant for endothelial cells. By contrast, lung fibroblasts and lung epithelial cells might preferentially undergo senescence upon irradiation. ${ }^{17,18}$ As fractionated irradiation-stimulated apoptosis in lung endothelial cells was accompanied by ATM-dependent activation of p53 as well as upregulation of the p53-regulated Fas $R$ gene, we hypothesize that $\mathrm{p53}$ is involved in this process.

Lovastatin accelerated the removal of radiation-induced DSBs in all three types of lung cells, suggesting that it stimulates DSB repair. Noteworthy, lovastatin also promotes DSB repair in human keratinocytes in vitro. ${ }^{42}$ Moreover, pravastatin improves the repair of radiation-induced DSBs in fibroblasts obtained from Huntington's disease patient's ${ }^{43}$ and atorvastatin accelerates the repair of oxidative DNA damage in smooth muscle cells. ${ }^{44}$ Additionally, lovastatin prevents DSB formation following treatment with topoisomerase type II poisons. ${ }^{11,45}$ Apparently, statins are genoprotective in vitro, which is at least partially due an improved DNA repair and/or 

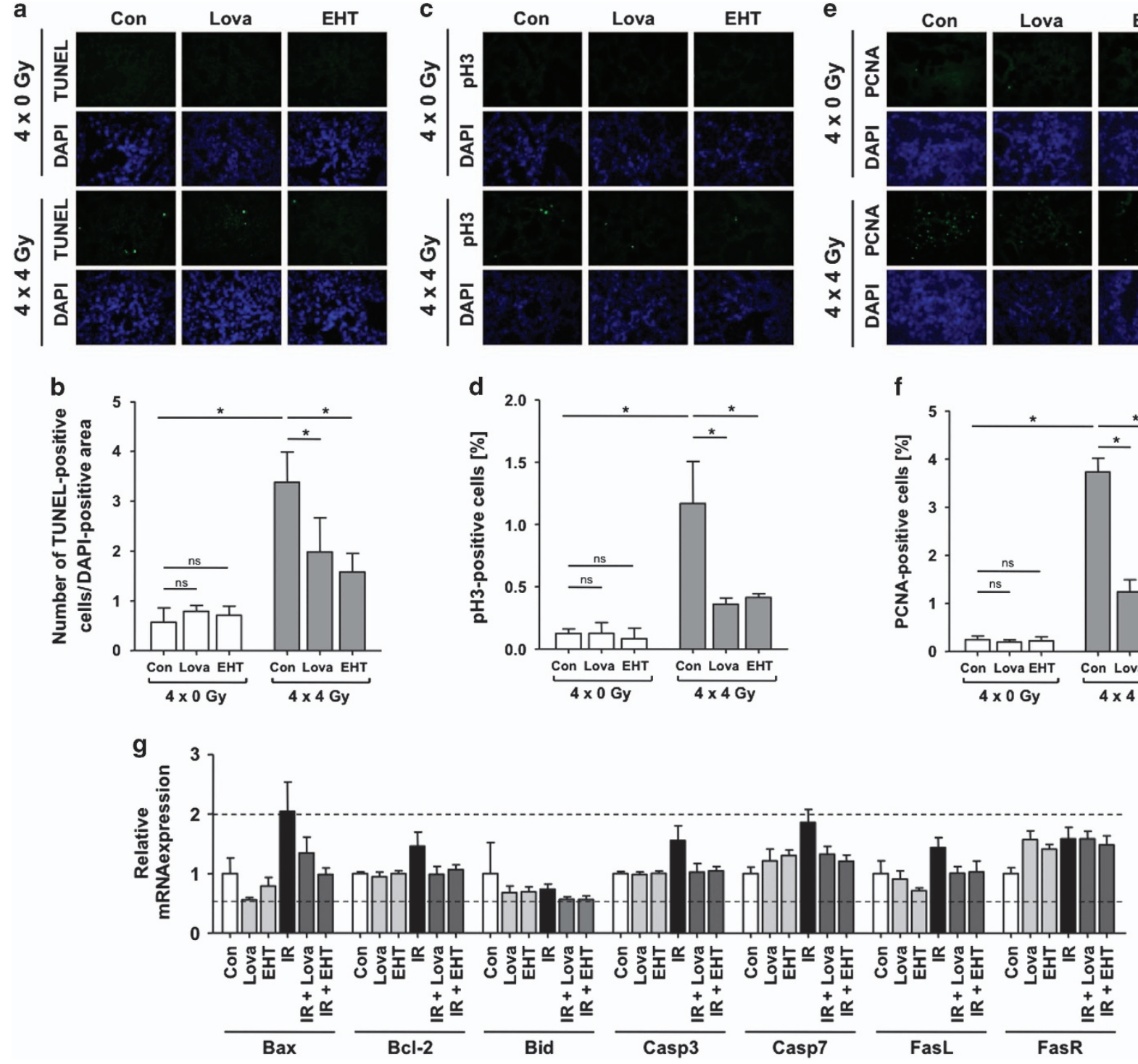
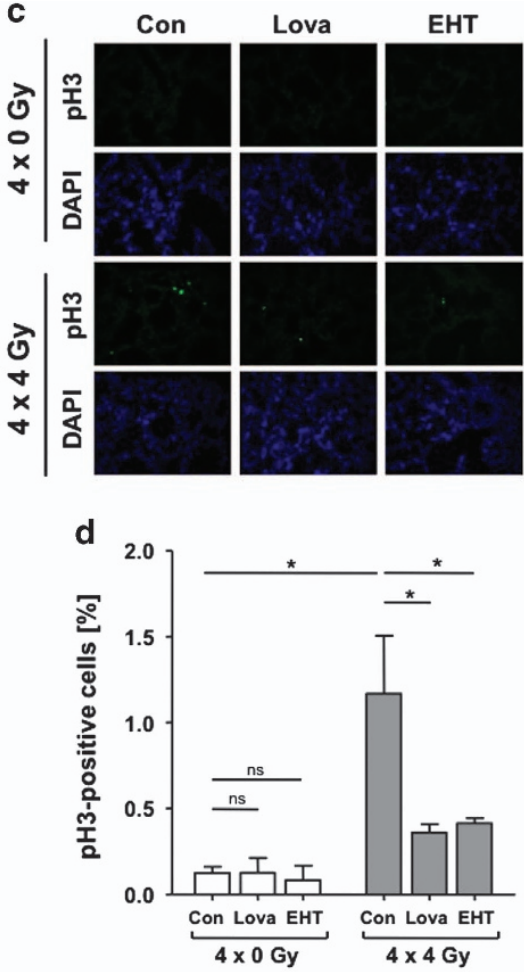
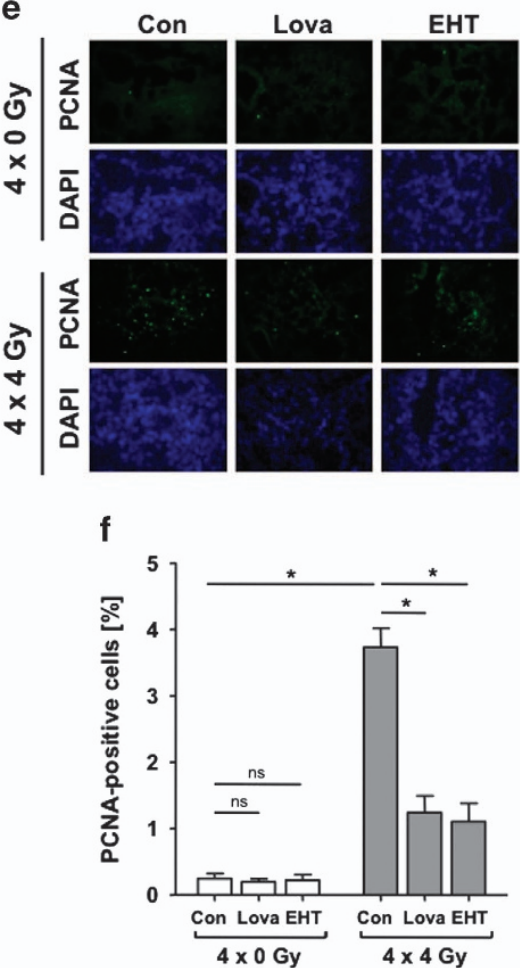

Figure 5 Lovastatin and EHT1864 attenuate IR-induced apoptosis and regenerative proliferation following fractionated irradiation of the lung. Male BALB/c mice were treated according to Figure $4 \mathrm{~b}$. Four weeks after the last irradiation the frequency of apoptotic cells (TUNEL), mitotic index (pH3) and cell proliferation (PCNA) were analyzed in the right lung. (a,b) Apoptotic frequency was determined using the TUNEL assay. (a) Representative image. Nuclei are stained by DAPI (blue). (b) Quantitative data are shown as the mean \pm S.D. from $n=4-6$ animals per experimental group. Two-way ANOVA with Bonferroni post hoc test, ${ }^{*} P \leq 0.05$. ns, not significant. (c, d) Mitotic index was investigated by detection of cells expressing Ser10 phosphorylated histone H3 (pH3). (c) Representative image. Nuclei are stained by DAPI (blue). (d) Quantitative data are shown as the mean \pm S.D. from $n=4-6$ animals per experimental group. Two-way ANOVA with Bonferroni post hoc test, ${ }^{*} P \leq 0.05$. ns, not significant. (e,f) Cell proliferation was investigated by immunohistochemistry-based staining of proliferating cell nuclear antigen (PCNA). (e) Representative images are shown. Nuclei are stained with DAPI (blue). (f) Quantitative data are shown as the mean+S.D. from $n=3$ animals per experimental group. Two-way ANOVA with Bonferroni post hoc test, ${ }^{*} P \leq 0.05$. ns, not significant. (g) mRNA levels of Bax, Bcl-2, Bid, caspases 3 (Casp3) and 7 (Casp7) as well as of Fas ligand (FasL) and Fas receptor (FasR) were analyzed using quantitative real-time PCR. Relative mRNA expression in non-irradiated animals was set to 1.0. mRNA expression of $\geq 2$ and $\leq 0.5$ as compared with control are marked with dashed lines. Shown are the mean \pm S.D. from pooled samples of $n=4-6$ animals per group $(N=3)$

protection from DNA damage formation. Since Rac1 is a relevant target of statins ${ }^{5}$ and, moreover, is present in the nucleus, ${ }^{46}$ we speculate that it interferes with the ATM/ATRregulated DDR. ${ }^{47}$ Accordingly, pharmacological inhibition of Rac1 blocks IR-stimulated ATM/Chk2 and ATR/Chk1 activity in pancreatic carcinoma cells. ${ }^{48,49}$ Interestingly, zoledronic acid, which inhibits farnesylpyrophosphate (FPP) synthesis, also promotes the repair of IR-induced DSBs in mesenchymal stem cells. ${ }^{50}$
To scrutinize the in vivo relevance of our in vitro data, we established a mouse model that enables a local and fractionated irradiation of the right lung and analyzed RILI at late time points (i.e., 4 weeks) after irradiation. Using this clinical designed protocol we found that inhibition of Rac1 signaling might mitigate acute radiation pneumonitis as observed two weeks after irradiation. At later time point, clear signs of persisting inflammation or sustained oxidative stress, as reflected by Nrf2-regulated activation of antioxidative 
a
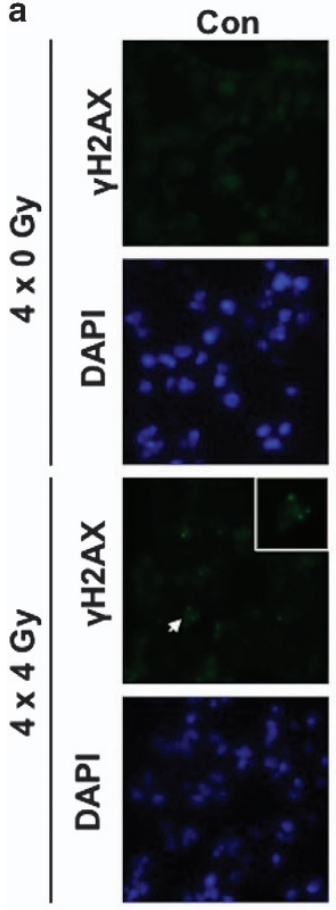

b
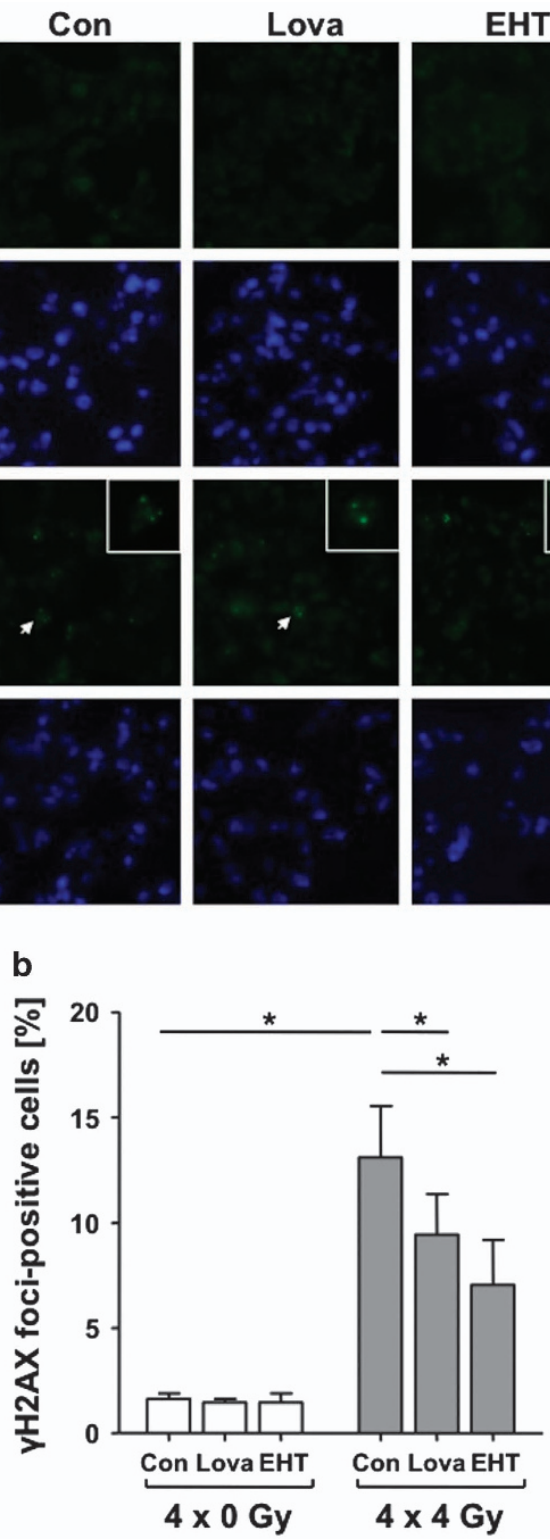

C
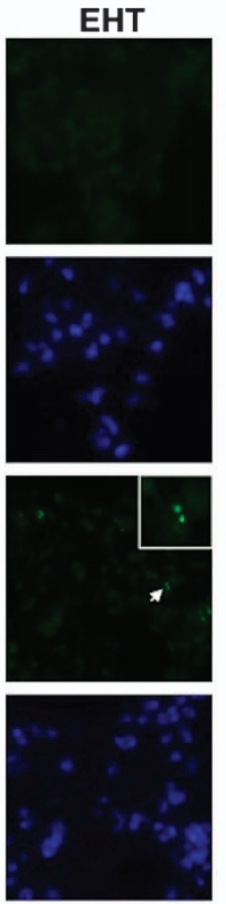

0
+
8
+
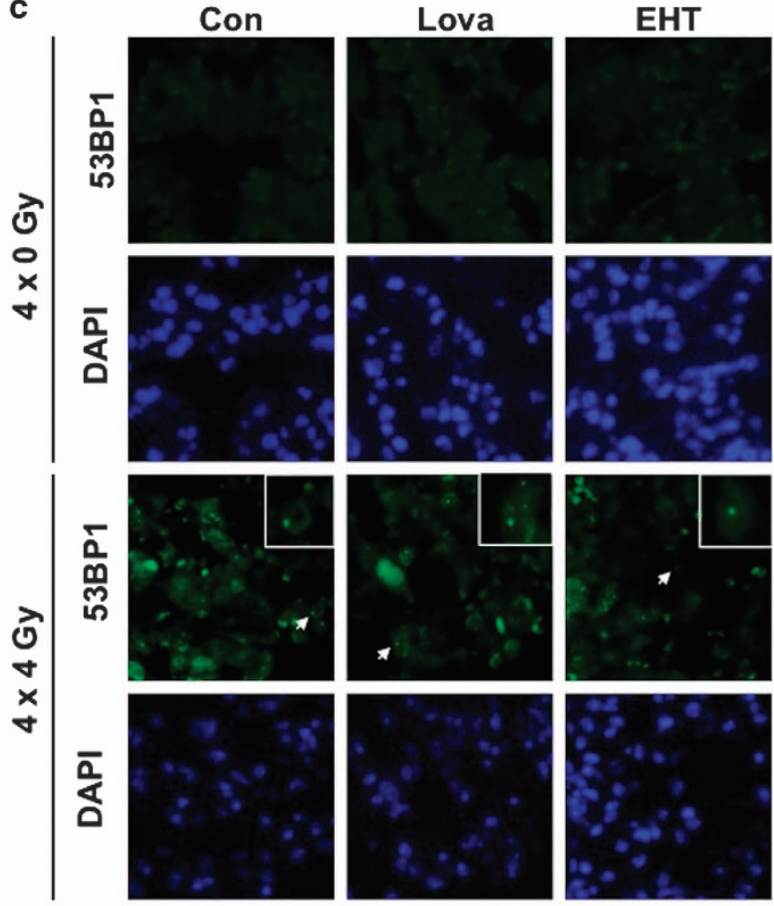

d

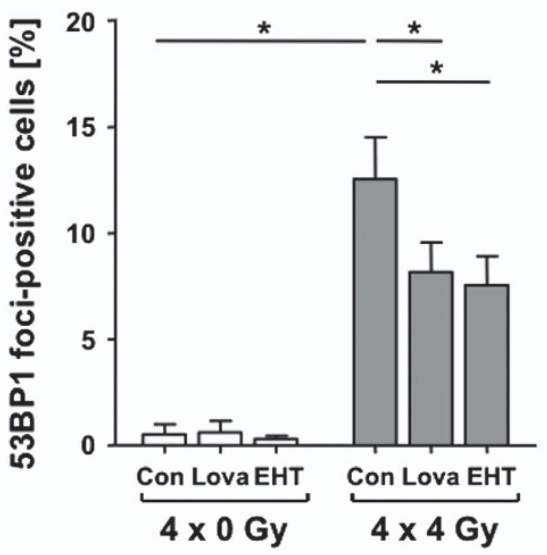

Figure 6 Lovastatin and EHT1864 attenuate the level of IR-induced residual DNA damage in lung tissue as reflected on the level of $\gamma$ H2AX-positive and 53BP1-positive cells. Male BALB/c mice were treated according to Figure 4b. Four weeks after the last irradiation nuclear $\gamma \mathrm{H} 2 \mathrm{AX}$ foci $(\mathbf{a}, \mathbf{b})$ and $53 \mathrm{BP} 1$ foci (c,d) were analyzed as surrogate markers of DSBs in the right lung. (a) Representative images. Nuclei were stained by DAPI (blue). Arrow points to a representative $\gamma \mathrm{H} 2 \mathrm{AX}$-positive cell (enlarged in the image detail). (b) Quantification of $\gamma \mathrm{H} 2 \mathrm{AX}$-positive cells in tissue of the right lung. Data shown are the mean \pm S.D. from $n=4-6$ mice per experimental group. Two-way ANOVA with Bonferroni post hoc test, ${ }^{*} P \leq 0.05$. (c) Representative images are shown. Nuclei were stained by DAPI (blue). Arrow points to a representative 53BP1-positive cell (this area is enlarged in the image detail). (d) Quantification of 53BP1-positive cells in tissue of the right lung. Data shown are the mean \pm S.D. from $n=3$ mice per experimental group. Two-way ANOVA with Bonferroni post hoc test, ${ }^{*} P \leq 0.05$

defense mechanisms, were not detectable anymore. Notably, statins are known to attenuate pro-fibrotic radiation responses after single high-dose irradiation ${ }^{4,15,16,51,52}$ and to reduce vascular leakage and leucocyte infiltration in a model of acute RILI. ${ }^{14}$ Thus, our data, together with these reports, further support the hypothesis of beneficial effects of statins on RILI.

The primary cytotoxic DNA damage induced by ionizing radiation are DSBs, which stimulate DDR mechanisms regulating cell cycle checkpoints, DNA repair, cell death and senescence. $^{20,33}$ The interplay between mechanisms of DNA repair, DDR and apoptosis or senescence is rather complex, ${ }^{22}$ with p53 being a major determinant of cell fate decision, and, moreover, mechanisms of resistance are manifold. ${ }^{53}$ Therefore, alterations in DNA repair do not necessarily go along with proportional changes in apoptosis. This might explain the cell type-specific diverse effects of lovastatin on IR-induced apoptosis and DSB repair. We hypothesize that pharmacological interference with (early) primary stress responses resulting from radiation-induced DNA damage is more effective regarding tissue protection than abrogation of (late) secondary responses. Consequently, acceleration of DSB repair or blockage of pro-apoptotic DDR is considered 

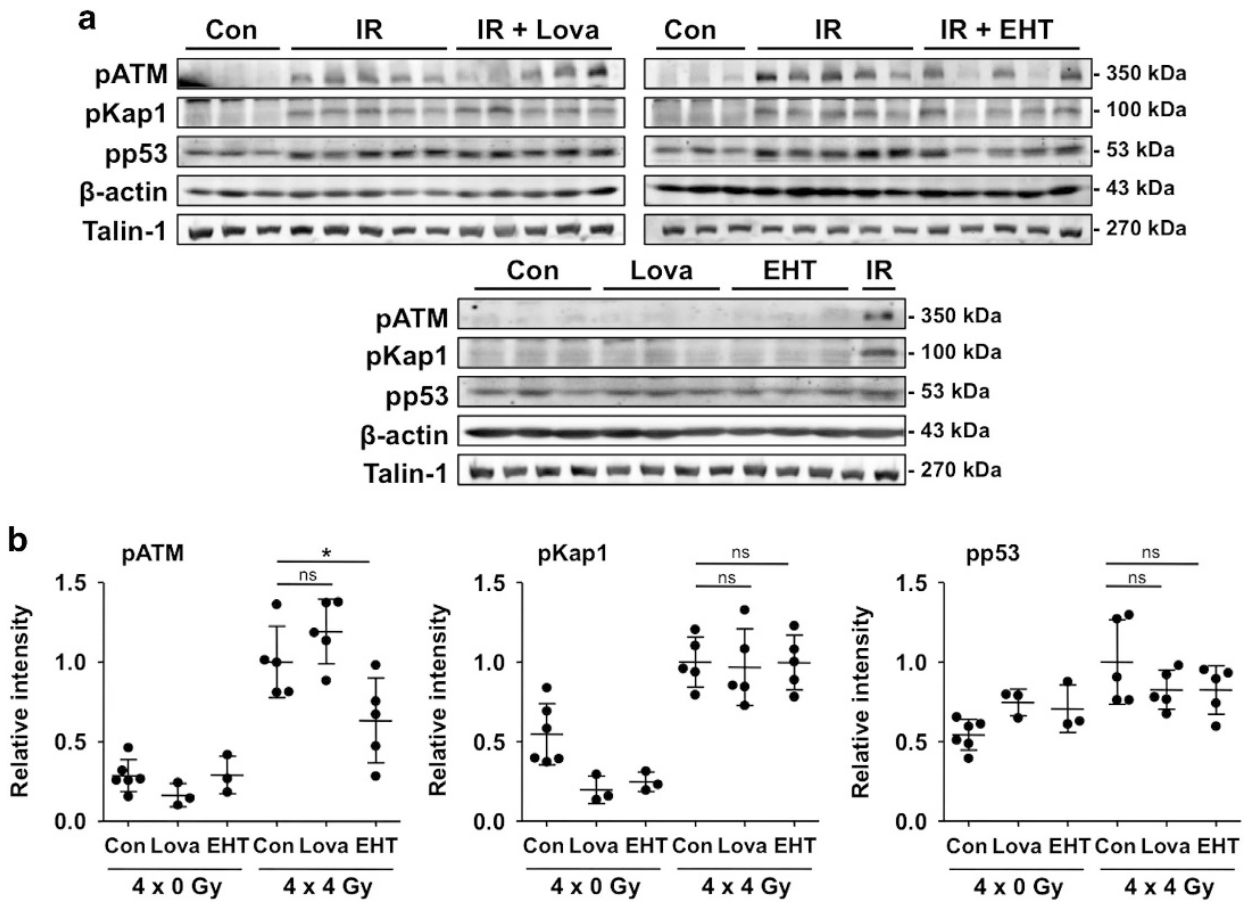

Figure 7 Fractionated irradiation causes a persistent activation of the DDR-related factors ATM, p53 and Kap-1 in lung tissue four weeks after the last irradiation. EHT1864 treatment significantly reduces the level of activated ATM. Male BALB/c mice were treated according to Figure 4b. Four weeks after the last irradiation the activation status of key proteins of the DNA damage response was analyzed in the right lung by western blot analysis. (a) Shown are the protein levels of Ser1981 phosphorylated (activated) ATM (pATM), Ser15 phosphorylated protein 53 (pp53) and Ser824 phosphorylated KRAB-associated protein-1 (pKap1). Results obtained from $n=3-5$ animals per group are presented. Expression of $\beta$-actin and Talin-1 were used as loading controls. (b) Densitometrical analysis of alterations in the protein levels of DDR factors. Relative expression in irradiated animals was set to 1.0. Data shown are obtained from $n=3-6$ animals per experimental group. Two-way ANOVA with Bonferroni post hoc test, ${ }^{*} P \leq 0.05$ (IR versus IR+Lova or IR versus IR+EHT). ns, not significant

as particular radioprotective. Noteworthy, lovastatin and EHT1864 significantly reduced the number of residual DSBs in lung tissue as detectable 4 weeks after the end of the fractionated irradiation. Because lovastatin does not affect the initial level of DSBs following irradiation, ${ }^{13,39}$ we assume that the statin and the Rac1 inhibitor accelerate the repair of IRinduced DSBs. In consequence, a mitigated pro-apoptotic DDR and a diminished need for regenerative processes is anticipated. Indeed, we observed both a lower frequency of apoptotic cells and a reduced mitotic index in irradiated animals if Rac1 signaling was pharmacologically inhibited. Because targeting of Rho/Rac1 signaling also prevents the formation of DSBs following topoisomerase II poisoning, ${ }^{11,45}$ we hypothesize that Rac1 interferes with both DNA damage induction and DNA repair, thereby eventually shutting down the primary stimulus (i.e., DNA damage) that triggers deathrelated DDR pathways. This hypothesis gains support by a recent report showing that epidermal Rac1 regulates DDR and repair following UV exposure, thereby protecting keratinocytes from apoptotic death. ${ }^{54}$

Taking into consideration the use of statins to alleviate adverse effects of radiotherapy, protection of tumor cells from DNA damage-triggered killing responses should be excluded. Fortunately, lovastatin did not attenuate IR-induced apoptosis in human breast cancer cells (MCF-7), which is a relevant cell type in the context of thoracic radiotherapy (Supplementary Figure 8). Additionally, statins augment the efficacy of various antitumor therapeutics in different tumor entities. ${ }^{55,56}$
Noteworthy, pitavastatin acts as a radiosensitizer for multiple tumor cell types including lung tumor cells ${ }^{57-59}$ and, furthermore, radiosensitization of breast carcinoma cells ${ }^{60}$ and head and neck squamous cell carcinoma (HNSCC) cells ${ }^{61}$ is achievable by Rac1 inhibition. The molecular basis for radiosensitization of tumor cells and concomitant radioprotection of normal cells by statins and/or Rac1 inhibition remains obscure. The fact that Rho-GTPases, including Rac1, are often overexpressed in malignant tissue as compared with the corresponding normal tissue ${ }^{62}$ might contribute to a different response of tumor versus normal cells. In extension to data that give preference to Rho/ROCK-regulated functions for radioprotection conferred by statins, ${ }^{4,16,51}$ we provide additional evidence that inhibition of Rac1 signaling contributes to the radioprotective effects of statins on subchronic lung damage following fractionated radiotherapy. While statinmediated inhibition of Rho/ROCK pathway impacts the late outcome of radiation injury (i.e., fibrosis), ${ }^{15,16,51}$ our data further indicate that statins also interfere with preceding radiotoxic effects (i.e., DNA damage and caspase-mediated apoptosis) by targeting Rac1 signaling. Lovastatin treatment of human endothelial cells largely reduced the level of GTPbound active Rac1 (Supplementary Figure 9), supporting the hypothesis of Rac1 as a major target of statin-mediated effects. Collectively, the data available support the view of multiple radioprotective effects of statins on normal tissue that might be useful in the clinic to widen the therapeutic window of radiotherapy. Although animals were given higher doses of 
lovastatin (30 mg/kg bw/week) than used for the treatment of hypercholesterolemic patients ( $5 \mathrm{mg} / \mathrm{kg}$ bw/week), even much higher statin doses (>150 mg/kg bw/week) are well tolerated in humans and do not provoke substantial adverse effects even under situation of long-term treatment. ${ }^{63-65}$

In conclusion, our study provides novel evidence of a radioprotective potency of lovastatin on normal primary human lung cells and rodent lung tissue under situation of hypo-fractionated irradiation, which is at least partially due to inhibition of Rac1 signaling. The data indicate that microvascular lung endothelial cells are particularly relevant for fractionated irradiation-induced lung damage and that lovastatin mediates protection from RILI. Further studies are preferential to investigate the impact of statins on chronic radiation-induced lung fibrosis. Moreover, the data encourage (i) retrospective or prospective clinical studies addressing the usefulness of statins in supportive care in radiotherapy and (ii) the development and preclinical analysis of novel Rac1-specific inhibitory drugs for radioprotection.

\begin{abstract}
Materials and Methods
Cell culture conditions and treatment of human cells. HMVEC-L were obtained from Lonza (Basel, Switzerland) and cultured in EGM-2MV medium. HPF and HSAEpC were purchased from PromoCell (Heidelberg, Germany) and cultured in Fibroblast Growth Medium 2 and Small Airway Epithelial Cell Growth Medium obtained from the provider, respectively. The cells were directly obtained from the aforementioned providers at passage P2 and were cultured in our laboratory for less than 6 months and $<15$ population doublings. HMVEC-L were authenticated by the provider by monitoring the expression of von Willebrand Factor VIII and PECAM as well as the uptake of acetylated low density lipoprotein. Also HSAEpC and HPF authentication was performed by the provider. Here, cell morphology and FACS-based analysis of cytokeratin (HSAEpC) and CD90 (HPF) expression were monitored. Human umbilical vein endothelial cells (HUVEC) and human breast cancer cells (MCF-7) originate from PromoCell and and the German Tissue Culture Collection (DSMZ, Braunschweig, Germany), respectively, and were cultured in Endothelial Cell Growth Medium 2 and Dulbecco's modified Eagle medium (Sigma, Steinheim, Germany), respectively. Human lung fibroblasts (MRC-5) cells were purchased from CLS Cell Lines Service (Heidelberg, Germany) and cultivated in Dulbecco's modified Eagle medium:Ham's F12 (1:1) (Biochrom, Berlin, Germany). Cells were kept at $37^{\circ} \mathrm{C}$ in a humidified atmosphere containing $5 \% \mathrm{CO}_{2}$. They were seeded in high density and grown for $72 \mathrm{~h}$ to ensure confluency before pretreatment with $5 \mu \mathrm{M}$ lovastatin (Sigma). The experiments were done at cell confluency because this reflects the in vivo situation. $24 \mathrm{~h}$ later medium was changed and lovastatin concentration was reduced to $1 \mu \mathrm{M}$ and cells were irradiated on four days in a row with 4 Gy $\left({ }^{137} \mathrm{Cs}\right.$ source (Gammacell 3000, Nordion, Ottawa, Canada)). This experimental setup was chosen to analyze the ability of lovastatin to favor the repair of potentially lethal damage (PLD) induced by fractionated irradiation.
\end{abstract}

Analysis of nuclear $\mathrm{yH} 2 \mathrm{AX}$ foci formation and determination of mitotic index. The formation of Ser139 phosphorylated histone $2 A X$ nuclear foci $(\gamma \mathrm{H} 2 \mathrm{AX}$ foci) was measured as surrogate marker of ionizing radiation (IR)-induced DNA double-strand breaks (DSBs) by immunofluorescence. Ser10 phosphorylation of histone $\mathrm{H} 3$ is a commonly used marker of mitotic index. Cells were fixed with $4 \%$ formaldehyde followed by overnight incubation with methanol $\left(-20^{\circ} \mathrm{C}\right)$. After blockage $(5 \% \mathrm{BSA}$ in $0.3 \%$ Triton X-100/PBS), cells were incubated with anti-Ser139 phosphorylated histone $2 \mathrm{AX}(\gamma \mathrm{H} 2 \mathrm{AX})$ antibody $\left(1: 500,16 \mathrm{~h}, 4^{\circ} \mathrm{C}\right)$ (Millipore, Billerica, MA, USA) or anti-Ser10 phosphorylated histone 3 antibody (pH3) (1:200, $\left.16 \mathrm{~h}, 4^{\circ} \mathrm{C}\right)$ (Thermo Fisher Scientific, Waltham, MA, USA). After washing, Alexa Fluor 488 goat anti-mouse IgG antibody (Rockland, Limerick, PA, USA) was added ( $90 \mathrm{~min}, \mathrm{RT})$. Cell nuclei were counterstained with DAPIcontaining Vectashield (Vector Laboratories, Burlingame, CA, USA) and $\gamma \mathrm{H} 2 \mathrm{AX}$ foci or pH3 positive cells were detected using Olympus BX43 microscope (Olympus, Hamburg, Germany).
Measurement of apoptotic cell death by Annexin V/PI staining. Apoptosis was analyzed by flow cytometer-based Annexin V/PI method. To this end, cells were resuspended in Annexin binding buffer (10 mM HEPES, $140 \mathrm{mM} \mathrm{NaCl}$, $2.5 \mathrm{mM}$ calcium chloride) and $10^{5}$ cells were incubated with $5 \mu$ l Fluoresceinconjugated Annexin V (Life Technologies, Carlsbad, CA, USA) (15 min, on ice). $10 \mu \mathrm{l}$ propidium iodide solution $(50 \mu \mathrm{g} / \mathrm{ml})$ and $200 \mu \mathrm{l}$ Annexin binding buffer were added before samples were analyzed by BD Accuri ${ }^{\mathrm{TM}} \mathrm{C} 6$ flow cytometer (BD, Franklin Lakes, NJ, USA) (530/30 nm and 585/40 nm filters). Cell morphology was monitored via light microscopy (Axiovert 40 CFL ((Zeiss, Jena, Germany)).

Animal experiments. Male BALB/c mice (12-16 weeks old, 20-30 g) were kept in the local animal housing facility of the University Hospital Düsseldorf (Germany). All animal experiments were approved by the local authorities (i.e., State Agency for Nature, Environment and Consumer protection, North Rhine-Westfalia, Germany; Reference number: 84-02.04.2013.A062) and performed according to the relevant guidelines and regulations. A total of six animals were randomized to each group. In line with previous studies ${ }^{6,14,66,67}$ animals were treated three times per week with lovastatin (10 mg/kg bw, p.o) (Betapharm Arzneimittel $\mathrm{GmbH}$, Augsburg, Germany) or the Rac1 small molecule inhibitor EHT1864 (5 mg/ $\mathrm{kg}$ bw, i.p.) (Tocris Bioscience, Bristol, UK) starting two days before the first irradiation dose and continuing till the end of the experiment (Figure 4b). Vehicletreated animals were used as control. Body weights were recorded three times per week. Fractionated local irradiation of the right lung was performed four times with each 4 Gy (cumulative dose: 16 Gy; biological effective dose (BED): 37.3 Gy) within two weeks. Before irradiation mice were anesthetized with ketamine (100 mg/kg bw) and xylazin (5 mg/kg bw). As irradiation device a Gulmay RS 225 (15 mA, $200 \mathrm{kV}$ ) was used. For the selective irradiation of the right lung, mice were adjusted into an irradiation device that allows selective irradiation of the right lung (Figure 4a) (radiation field: $1.26 \mathrm{~cm}^{2}$ ). Control mice were subjected to sham irradiation.

Analysis of breathing frequency. Breathing frequency was monitored two and four weeks after the last irradiation. To this end, mice were anesthetized as described above and breathing frequency was determined 15 min later by two independent investigators (recording for one minute and calculation of mean values).

Histological and immunohistochemical analyses. Formaldehydefixed paraffin-embedded lung tissue samples were cut into $4 \mu \mathrm{m}$ sections. Paraffin removal and tissue rehydration was performed according to standard procedures. To evaluate inflammation and fibrosis, sections were stained with hematoxylin/eosin (HE) (Sigma-Aldrich, Steinheim, Germany) and Sirius Red (Waldeck, Münster, Germany), respectively. For Nrf2 staining sections were incubated in $3 \% \mathrm{H}_{2} \mathrm{O}_{2}$ for $20 \mathrm{~min}$, boiled in Target Retrieval Solution (DAKO, Hamburg, Germany) for $30 \mathrm{~min}$ and blocked in TNB buffer (PerkinElmer, Waltham, MA, USA) for $30 \mathrm{~min}$. Afterwards, samples were incubated with $0.001 \%$ avidin and $0.001 \%$ biotin $(15 \mathrm{~min}$ each) before rabbit anti-Nrf2 antibody (1:1000; Santa Cruz, CA, USA) was added $\left(4^{\circ} \mathrm{C}\right.$ overnight). After washing, sections were incubated with biotinylated donkey anti-rabbit lgG (Santa Cruz, CA, USA) (1:200, 45 min at RT). Afterwards TSA Biotin Kit (PerkinElmer) was used according to the manufacturer's instructions and sections were incubated with $A B C$ reagent (Vectastain Elite $A B C$ HRP Kit, Vector Laboratories, Burlingame, CA, USA) and stained with 3,3'-diaminobenzidine (DAB Peroxidase Substrate Kit (Vector Laboratories)) for $90 \mathrm{~s}$. Sections were counterstained with hematoxylin, mounted in Entellan and evaluated using Olympus BX43 microscope. For immunofluorescent stainings epitopes were demasked by incubation with Target Retrieval Solution (DAKO, Hamburg, Germany) in a steam boiler $(1 \mathrm{~h})$ before blocking in Protein Block (DAKO, Hamburg, Germany) $(1 \mathrm{~h})$. Incubation with primary antibody was performed overnight $\left(4^{\circ} \mathrm{C}\right.$, wet chamber). The following antibodies were used: rabbit anti-Ser139 phosphorylated histone $2 \mathrm{AX}$ (1:400 Abcam, Cambridge, MA, USA) and anti-53BP1 (1:400, Cell Signaling, Beverly, MA, USA) to detect DNA damage; rabbit anti-Ser10 phosphorylated histone 3 (1:250, Thermo Fisher Scientific) to monitor mitotic index; mouse anti-proliferating cell nuclear antigen (PCNA) (Millipore) to analyze proliferation, rabbit anti-CD68 $(1: 100, A b c a m)$ to detect macrophages. After washing (PBS/0.1\% Tween 20 $(3 \times 5 \mathrm{~min}))$ Alexa Fluor 488 -coupled goat anti-rabbit secondary antibody (Invitrogen, Darmstadt, Germany) was used. Sections were mounted in DAPI-containing Vectashield and evaluated with Olympus BX43 microscope.

Analysis of apoptosis by TUNEL assay. Apoptotic cells were detected by the In Situ Cell Death Detection Kit Fluorescein (Roche, Mannheim, Germany) 
according to the manufacturer's instructions. Protein digestion was performed with $20 \mu \mathrm{g} / \mathrm{ml}$ Proteinase K (Qiagen, Hilden, Germany). As positive control treatment with $150 \mathrm{U} / \mathrm{ml}$ DNase (Qiagen) was performed. Nuclei were counterstained with DAPIcontaining Vectashield and analyzed with Olympus BX43 microscope.

Total RNA purification, cDNA synthesis and qRT-PCR analysis. Total RNA from 10-20 mg lung tissue or $1-5 \times 10^{6}$ cells was isolated using the RNeasy Mini Kit (Qiagen). RNA yield and purity were determined with NanoVue Plus Spectrophotometer (GE Healthcare, Freiburg, Germany). RNA was isolated from $n=4-6$ animals per experimental group and pooled in equal amounts for CDNA synthesis using High-Capacity CDNA Reverse Transcription Kit (Applied Biosystems, Darmstadt, Germany). For each cDNA synthesis reaction 1000-2000 ng of total RNA was used. Quantitative real-time PCR analysis (triplicate determinations) was accomplished with $20 \mathrm{ng}$ cDNA using CFX96 Touch Real-Time PCR Detection System (Bio-Rad Laboratories, Hercules, CA, USA). A semi-customized PCR-array (Sigma-Aldrich) containing 29 selected genes (Supplementary Table 1) involved in inflammation and fibrosis was used for quantitative mRNA analyses. Moreover, primers for selected oxidative stress and apoptosis-related genes were synthesized by Eurofins (Ebersberg, Germany). mRNA levels of target genes were normalized to that of the housekeeping genes glyceraldehyde 3-phosphate dehydrogenase (GAPDH), beta actin ( $\beta$-actin) and ribosomal protein L32 (RPL32). 45 amplification cycles were performed (each cycle: $95^{\circ} \mathrm{C}-15 \mathrm{~s} ; 55^{\circ} \mathrm{C}-15 \mathrm{~s} ; 72^{\circ} \mathrm{C}-17 \mathrm{~s}$ ). Following each run a melt curve analysis was included to ensure product specificity. PCR products with threshold cycles of $\geq 36$ were omitted. Gene expression of control animals was set to 1. Data analysis was performed with the CFX Manager Software (Bio-Rad Laboratories). Alterations in mRNA expression of $\geq 2$ and $\leq 0.5$ as compared with untreated control animals (set to 1.0) are considered as particularly relevant and are marked with dashed lines.

Preparation of protein extracts and western blot analysis. To prepare total protein extracts 10-20 mg lung tissue was homogenized (lysis buffer: $50 \mathrm{mM}$ Tris $\mathrm{HCl}, 150 \mathrm{mM} \mathrm{NaCl}, 2 \mathrm{mM}$ EDTA, 1\% NP 40, 0.1\% sodium dodecyl sulfate, $1 \%$ sodium desoxycholate, $1 \mathrm{mM}$ sodium orthovanadate, $1 \mathrm{mM}$ phenylmethylsulfonyl fluoride, $50 \mathrm{mM}$ sodium fluoride and $1 \mathrm{x}$ Protease inhibitor cocktail (Cell Signaling)) with Tissue Lyzer II (Qiagen) and sonicated on ice before centrifugation $\left(10 \mathrm{~min}\right.$ at $\left.10.000 \times \mathrm{g}, 4^{\circ} \mathrm{C}\right)$. Protein concentration of the supernatant was determined with the DC Protein Assay (Bio-Rad Laboratories). Protein samples were diluted with Roti-Load 1 (Roth, Karlsruhe, Germany) and heated $\left(95^{\circ} \mathrm{C}\right.$, $5 \mathrm{~min}) .30-100 \mu \mathrm{g}$ of total protein was separated by SDS-PAGE (6-15\% gels) and transferred onto nitrocellulose membranes (GE Healthcare, Freiburg, Germany) using Mini-PROTEAN electrophoresis chamber (Bio-Rad Laboratories). After blocking of membranes ( $5 \%$ dry milk in TBS $/ 0.1 \%$ Tween $20,2 \mathrm{~h}$ ), incubation with primary antibody $(1: 1000)$ was performed (overnight, $4{ }^{\circ} \mathrm{C}$ ). After incubation with HRP-conjugated secondary antibodies (1:2000, Rockland Immunochemicals Inc., Limerick, Pam USA) (2 h, RT), bound antibodies were visualized by chemiluminescence using the Fusion FX7 imaging system (Vilber Lourmat, Eberhardzell, Germany) or ChemiDoc Imaging System (Bio-Rad Laboratories). The following primary antibodies were used: anti-Ser15 phosphorylated protein 53 (pp53), anti-Ser345 phosphorylated checkpoint kinase 1 (pChk1) anti-caspase 3, anti-activated caspase 3 and 7, Talin-1 (Cell Signaling), anti-Ser824 phosphorylated KRAB-associated protein-1 (pKap1) (Bethyl Laboratories Inc., Montgomery, TX, USA), anti-Ser1981 phosphorylated Ataxia telangiectasia mutated (pATM), antiThr68 phosphorylated checkpoint kinase-2 (pChk2), (Abcam), anti-Bax, anti-Bcl-2, anti-XIAP, anti- $\beta$-actin and anti-Poly(ADP-ribose)-polymerase 1 (PARP-1) antibodies (Santa Cruz).

Active Rac1 pull-down assay. The level of active Rac1 was analyzed by Rac1 pull-down assay, which measures the binding of GTP-bound (active) Rac1 to its effector protein p21-associated protein kinase 1 (PAK1). To this end, GST-fused PAK1-GTPase-binding domain, which was isolated after recombinant expression in Escherichia coli, was used. GSH sepharose beads (GE Healthcare, Little Chalfont,

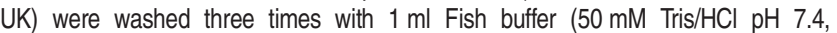
$100 \mathrm{mM} \mathrm{NaCl}, 2 \mathrm{mM} \mathrm{MgCl}$, $1 \%$ Igepal Ca-630, $10 \%$ glycerol, $20 \mathrm{mM}$ betaglycerophosphate, $1 \mathrm{mM}$ sodium orthovanadate $\mathrm{Na}_{3} \mathrm{VO}_{4}, 1$ tablet complete, EDTAfree Protease Inhibitor Cocktail (Roche, Basel, Switzerland)) and equal amounts of bacterial lysates containing GST (negative control) or GST-fused PAK1-GTPasebinding domain were added to the beads and incubated for $1 \mathrm{~h}$ at $4{ }^{\circ} \mathrm{C}$, followed by another three times washing with Fish buffer. HUVEC total cell lysate was obtained from two confluent $10 \mathrm{~cm}$ dishes, added to the GST or GST-PAK1-bound sepharose beads and incubated for $30 \mathrm{~min}$ at $4{ }^{\circ} \mathrm{C}$. The samples were washed three times with Fish buffer and Roti-Load 1 (Roth, Karlsruhe, Germany) was added to the samples before heat denaturation for $10 \mathrm{~min}$ at $95{ }^{\circ} \mathrm{C}$ was performed. Samples were analyzed by SDS-PAGE and immunoblotting as described above. Mouse anti-Rac1 antibody (1:2500) from Millipore was used for the detection of Rac1.

Statistical analysis. Results are expressed as mean \pm S.D. For statistical analysis, experimental groups were compared by two-way analysis of variance (ANOVA) with Bonferroni post hoc test using GraphPad Prism 5 (GraphPad Software Inc., La Jolla, CA, USA). A $P$-value of $P \leq 0.05$ was defined as level of significance.

\section{Conflict of Interest}

The authors declare no conflict of interest.

Acknowledgements. We acknowledge the excellent technical support of Christoph Stasch (Department of Radiotherapy and Radiation Oncology, Medical Faculty, HHU, Duesseldorf) and Detlev Rohrbach (Department of Pharmacology, Medical Faculty, HHU, Duesseldorf) for the construction of the shielding device. The work was supported by the Wilhelm Sander-Stiftung (2012.063.1) and by the International Research Training Group IRTG 1902.

\section{Publisher's Note}

Springer Nature remains neutral with regard to jurisdictional claims in published maps and institutional affiliations.

1. Benveniste MF, Welsh J, Godoy MC, Betancourt SL, Mawlawi OR, Munden RF. New era of radiotherapy: an update in radiation-induced lung disease. Clin Radiol 2013; 68: e275-e290.

2. Liao JK, Laufs U. Pleiotropic effects of statins. Annu Rev Pharmacol Toxicol 2005; 45 : 89-118.

3. Zhou Q, Liao JK. Pleiotropic effects of statins. - Basic research and clinical perspectives. Circ J 2010; 74: 818-826.

4. Haydont V, Bourgier C, Vozenin-Brotons MC. Rho/ROCK pathway as a molecular target for modulation of intestinal radiation-induced toxicity. Br J Radiol 2007; 80: 32-40.

5. Rashid M, Tawara S, Fukumoto Y, Seto M, Yano K, Shimokawa H. Importance of Rac1 signaling pathway inhibition in the pleiotropic effects of HMG-CoA reductase inhibitors. Circ $J$ 2009; 73: 361-370

6. Huelsenbeck J, Henninger C, Schad A, Lackner KJ, Kaina B, Fritz G. Inhibition of Rac1 signaling by lovastatin protects against anthracycline-induced cardiac toxicity. Cell Death Dis 2011; 2: e190.

7. Fritz G, Kaina B. Rho GTPases: promising cellular targets for novel anticancer drugs. Curr Cancer Drug Targets 2006; 6: 1-14.

8. Graaf MR, Richel DJ, van Noorden CJ, Guchelaar HJ. Effects of statins and farnesyltransferase inhibitors on the development and progression of cancer. Cancer Treat Rev 2004; 30: 609-641.

9. Chan KK, Oza AM, Siu LL. The statins as anticancer agents. Clin Cancer Res 2003; 9: 10-19.

10. Riad A, Bien S, Westermann D, Becher PM, Loya K, Landmesser U et al. Pretreatment with statin attenuates the cardiotoxicity of Doxorubicin in mice. Cancer Res 2009; 69: 695-699.

11. Huelsenbeck SC, Schorr A, Roos WP, Huelsenbeck J, Henninger C, Kaina B et al. Rac1 protein signaling is required for DNA damage response stimulated by topoisomerase II poisons. J Biol Chem 2012; 287: 38590-38599.

12. Damrot J, Nubel T, Epe B, Roos WP, Kaina B, Fritz G. Lovastatin protects human endothelial cells from the genotoxic and cytotoxic effects of the anticancer drugs doxorubicin and etoposide. Br J Pharmacol 2006; 149: 988-997.

13. Nubel T, Damrot J, Roos WP, Kaina B, Fritz G. Lovastatin protects human endothelial cells from killing by ionizing radiation without impairing induction and repair of DNA doublestrand breaks. Clin Cancer Res 2006; 12: 933-939.

14. Mathew B, Huang $Y$, Jacobson JR, Berdyshev E, Gerhold LM, Wang T et al. Simvastatin attenuates radiation-induced murine lung injury and dysregulated lung gene expression. $A m$ $J$ Respir Cell Mol Biol 2011; 44: 415-422.

15. Haydont V, Gilliot O, Rivera S, Bourgier C, Francois A, Aigueperse $\mathrm{J}$ et al. Successful mitigation of delayed intestinal radiation injury using pravastatin is not associated with acute injury improvement or tumor protection. Int J Radiat Oncol Biol Phys 2007; 68: 1471-1482.

16. Haydont V, Bourgier C, Pocard M, Lusinchi A, Aigueperse J, Mathe D et al. Pravastatin Inhibits the Rho/CCN2/extracellular matrix cascade in human fibrosis explants and improves radiation-induced intestinal fibrosis in rats. Clin Cancer Res 2007; 13: 5331-5340.

17. Wang $Y$, Scheiber MN, Neumann C, Calin GA, Zhou D. MicroRNA regulation of ionizing radiation-induced premature senescence. Int J Radiat Oncol Biol Phys 2011; 81: 839-848.

18. Citrin DE, Shankavaram U, Horton JA, Shield W 3rd, Zhao S, Asano H et al. Role of type II pneumocyte senescence in radiation-induced lung fibrosis. J Natl Cancer Inst 2013; 105: 1474-1484. 
19. Roos WP, Kaina B. DNA damage-induced cell death by apoptosis. Trends Mol Med 2006; 12 $440-450$.

20. Roos WP, Kaina B. DNA damage-induced cell death: from specific DNA lesions to the DNA damage response and apoptosis. Cancer Lett 2013; 332: 237-248.

21. Olive PL. Detection of DNA damage in individual cells by analysis of histone $H 2 A X$ phosphorylation. Methods Cell Biol 2004; 75: 355-373.

22. Roos WP, Thomas AD, Kaina B. DNA damage and the balance between survival and death in cancer biology. Nat Rev Cancer 2016; 16: 20-33.

23. Shutes A, Onesto C, Picard V, Leblond B, Schweighoffer F, Der CJ. Specificity and mechanism of action of EHT 1864, a novel small molecule inhibitor of Rac family small GTPases. J Biol Chem 2007; 282: 35666-35678.

24. Liao ZX, Travis EL, Tucker SL. Damage and morbidity from pneumonitis after irradiation of partial volumes of mouse lung. Int J Radiat Oncol Biol Phys 1995; 32: 1359-1370.

25. Para AE, Bezjak A, Yeung IW, Van Dyk J, Hill RP. Effects of genistein following fractionated lung irradiation in mice. Radiother Oncol 2009; 92: 500-510.

26. Eldh T, Heinzelmann F, Velalakan A, Budach W, Belka C, Jendrossek V. Radiation-induced changes in breathing frequency and lung histology of C57BL/6 J mice are time- and dosedependent. Strahlenther Onkol 2012; 188: 274-281.

27. Ding NH, Li JJ, Sun LQ. Molecular mechanisms and treatment of radiation-induced lung fibrosis. Curr Drug Targets 2013; 14: 1347-1356.

28. Singh S, Vrishni S, Singh BK, Rahman I, Kakkar P. Nrf2-ARE stress response mechanism: a control point in oxidative stress-mediated dysfunctions and chronic inflammatory diseases. Free Radic Res 2010; 44: 1267-1288.

29. Epperly M, Bray J, Kraeger S, Zwacka R, Engelhardt J, Travis E et al. Prevention of late effects of irradiation lung damage by manganese superoxide dismutase gene therapy. Gene Ther 1998; 5: 196-208.

30. Kang SK, Rabbani ZN, Folz RJ, Golson ML, Huang H, Yu D et al. Overexpression of extracellular superoxide dismutase protects mice from radiation-induced lung injury. Int $J$ Radiat Oncol Biol Phys 2003; 57: 1056-1066.

31. Antonic V, Rabbani ZN, Jackson IL, Vujaskovic Z. Subcutaneous administration of bovine superoxide dismutase protects lungs from radiation-induced lung injury. Free Radic Res 2015; 49: 1259-1268.

32. Jeggo P, Lavin MF. Cellular radiosensitivity: how much better do we understand it? Int $J$ Radiat Biol 2009; 85: 1061-1081.

33. Harper JW, Elledge SJ. The DNA damage response: ten years after. Mol Cell 2007; 28 : 739-745.

34. Zhou BB, Elledge SJ. The DNA damage response: putting checkpoints in perspective. Nature 2000; 408: 433-439.

35. Shiloh Y. ATM and ATR: networking cellular responses to DNA damage. Curr Opin Genet Dev 2001; 11: 71-77.

36. Kim JW, Rhee CK, Kim TJ, Kim YH, Lee SH, Yoon HK et al. Effect of pravastatin on bleomycin-induced acute lung injury and pulmonary fibrosis. Clin Exp Pharmacol Physiol 2010; 37: 1055-1063

37. Zhu B, Ma AQ, Yang L, Dang XM. Atorvastatin attenuates bleomycin-induced pulmonary fibrosis via suppressing iNOS expression and the CTGF (CCN2)/ERK signaling pathway. Int J Mol Sci 2013; 14: 24476-24491.

38. Monceau V, Pasinetti N, Schupp C, Pouzoulet F, Opolon P, Vozenin MC. Modulation of the Rho/ROCK pathway in heart and lung after thorax irradiation reveals targets to improve normal tissue toxicity. Curr Drug Targets 2010; 11: 1395-1404.

39. Ostrau C, Hulsenbeck J, Herzog M, Schad A, Torzewski M, Lackner KJ et al. Lovastatin attenuates ionizing radiation-induced normal tissue damage in vivo. Radiother Oncol 2009; 92: $492-499$.

40. Ran XZ, Ran X, Zong ZW, Liu DQ, Xiang GM, Su YP et al. Protective effect of atorvastatin on radiation-induced vascular endothelial cell injury in vitro. J Radiat Res 2010; 51: 527-533.

41. Gaugler MH, Vereycken-Holler V, Squiban C, Vandamme M, Vozenin-Brotons MC, Benderitter M. Pravastatin limits endothelial activation after irradiation and decreases the resulting inflammatory and thrombotic responses. Radiat Res 2005; 163: 479-487.

42. Ziegler V, Albers A, Fritz G. Lovastatin protects keratinocytes from DNA damage-related proapoptotic stress responses stimulated by anticancer therapeutics. Biochim Biophys Acta 2016; 1863: 1082-1092

43. Ferlazzo ML, Sonzogni L, Granzotto A, Bodgi L, Lartin O, Devic C et al. Mutations of the Huntington's disease protein impact on the ATM-dependent signaling and repair pathways of the radiation-induced DNA double-strand breaks: corrective effect of statins and bisphosphonates. Mol Neurobiol 2014; 49: 1200-1211.

44. Mahmoudi M, Gorenne I, Mercer J, Figg N, Littlewood T, Bennett M. Statins use a novel Nijmegen breakage syndrome-1-dependent pathway to accelerate DNA repair in vascular smooth muscle cells. Circ Res 2008; 103: 717-725.

45. Wartlick F, Bopp A, Henninger C, Fritz G. DNA damage response (DDR) induced by topoisomerase II poisons requires nuclear function of the small GTPase Rac. Biochim Biophys Acta 2013; 1833: 3093-3103.

46. Sandrock K, Bielek H, Schradi K, Schmidt G, Klugbauer N. The nuclear import of the small GTPase Rac1 is mediated by the direct interaction with karyopherin alpha2. Traffic 2010; 11: 198-209.
47. Fritz G, Henninger $C$. Rho GTPases: novel players in the regulation of the DNA damage response? Biomolecules 2015; 5: 2417-2434.

48. Yan Y, Hein AL, Etekpo A, Burchett KM, Lin C, Enke CA et al. Inhibition of RAC1 GTPase sensitizes pancreatic cancer cells to gamma-irradiation. Oncotarget 2014; 5: 10251-10270.

49. Yan Y, Greer PM, Cao PT, Kolb RH, Cowan KH. RAC1 GTPase plays an important role in gamma-irradiation induced G2/M checkpoint activation. Breast Cancer Res 2012; 14: R60.

50. Misra J, Mohanty ST, Madan S, Fernandes JA, Hal Ebetino F, Russell RG et al. Zoledronate attenuates accumulation of DNA damage in mesenchymal stem cells and protects their function. Stem Cells 2016; 34: 756-767.

51. Bourgier C, Haydont V, Milliat F, Francois A, Holler V, Lasser P et al. Inhibition of Rho kinase modulates radiation induced fibrogenic phenotype in intestinal smooth muscle cells through alteration of the cytoskeleton and connective tissue growth factor expression. Gut 2005; 54: 336-343.

52. Haydont V, Mathe D, Bourgier C, Abdelali J, Aigueperse J, Bourhis J et al. Induction of CTGF by TGF-beta1 in normal and radiation enteritis human smooth muscle cells: Smad/Rho balance and therapeutic perspectives. Radiother Oncol 2005; 76: 219-225.

53. Galluzzi L, Senovilla L, Vitale I, Michels J, Martins I, Kepp 0 et al. Molecular mechanisms of cisplatin resistance. Oncogene 2012; 31: 1869-1883.

54. Deshmukh J, Pofahl R, Haase I. Epidermal Rac1 regulates the DNA damage response and protects from UV-light-induced keratinocyte apoptosis and skin carcinogenesis. Cell Death Dis 2017; 8: e2664.

55. Osmak M. Statins and cancer: current and future prospects. Cancer Lett 2012; 324: 1-12.

56. Fritz G. HMG-CoA reductase inhibitors (statins) as anticancer drugs (review). Int J Oncol 2005; 27: 1401-1409.

57. He Z, Mangala LS, Theriot CA, Rohde LH, Wu H, Zhang Y. Cell killing and radiosensitizing effects of atorvastatin in PC3 prostate cancer cells. Journal of radiation research 2012; 53: 225-233.

58. Tsuboi $\mathrm{Y}$, Kurimoto $\mathrm{M}$, Nagai $\mathrm{S}$, Hayakawa $\mathrm{Y}$, Kamiyama $\mathrm{H}$, Hayashi $\mathrm{N}$ et al. Induction of autophagic cell death and radiosensitization by the pharmacological inhibition of nuclear factor-kappa B activation in human glioma cell lines. J Neurosurg 2009; 110: 594-604.

59. Sanli T, Liu C, Rashid A, Hopmans SN, Tsiani E, Schultz C et al. Lovastatin sensitizes lung cancer cells to ionizing radiation: modulation of molecular pathways of radioresistance and tumor suppression. J Thorac Oncol 2011; 6: 439-450.

60. Hein AL, Post CM, Sheinin YM, Lakshmanan I, Natarajan A, Enke CA et al. RAC1 GTPase promotes the survival of breast cancer cells in response to hyper-fractionated radiation treatment. Oncogene 2016; 35: 6319-6329.

61. Skvortsov S, Dudas J, Eichberger P, Witsch-Baumgartner M, Loeffler-Ragg J, Pritz C et al. Rac1 as a potential therapeutic target for chemo-radioresistant head and neck squamous cell carcinomas (HNSCC). Br J Cancer 2014; 110: 2677-2687.

62. Fritz G, Just I, Kaina B. Rho GTPases are over-expressed in human tumors. Int J Cancer 1999; 81: 682-687.

63. Thibault A, Samid D, Tompkins AC, Figg WD, Cooper MR, Hohl RJ et al. Phase I study of lovastatin, an inhibitor of the mevalonate pathway, in patients with cancer. Clin Cancer Res 1996; 2: 483-491.

64. Armitage J. The safety of statins in clinical practice. Lancet 2007; 370: 1781-1790.

65. Holstein SA, Knapp HR, Clamon GH, Murry DJ, Hohl RJ. Pharmacodynamic effects of high dose lovastatin in subjects with advanced malignancies. Cancer Chemother Pharmacol 2006; 57: 155-164.

66. Henninger C, Huelsenbeck J, Huelsenbeck S, Grosch S, Schad A, Lackner KJ et al. The lipid lowering drug lovastatin protects against doxorubicin-induced hepatotoxicity. Toxicol Appl Pharmacol 2012; 261: 66-73.

67. Henninger C, Huelsenbeck S, Wenzel P, Brand M, Huelsenbeck J, Schad A et al. Chronic heart damage following doxorubicin treatment is alleviated by lovastatin. Pharmacol Res 2015; 91: 47-56.

68. Heinzelmann $\mathrm{F}$, Jendrossek V, Lauber $\mathrm{K}$, Nowak K, Eldh T, Boras $\mathrm{R}$ et al. Irradiation-induced pneumonitis mediated by the CD95/CD95-ligand system. J Natl Cancer Inst2006; 98: 1248-1251.

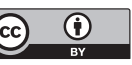

Cell Death and Disease is an open-access journal published by Nature Publishing Group. This work is licensed under a Creative Commons Attribution 4.0 International License. The images or other third party material in this article are included in the article's Creative Commons license, unless indicated otherwise in the credit line; if the material is not included under the Creative Commons license, users will need to obtain permission from the license holder to reproduce the material. To view a copy of this license, visit http://creativecommons.org/licenses/by/4.0/

(C) The Author(s) 2017 